\title{
O GERENCIAMENTO DA COMUNICAÇÃO DE PROJETOS PÚBLICOS: COMO ADAPTAR OS PROCESSOS DO PMBOK/PMI À REALIDADE DA ADMINISTRAÇÃO PÚBLICA
}

\author{
Alinne Silva e Quadros, Hélio Gomes de Carvalho \\ Mestrado em Planejamento e Governança Pública da Universidade Tecnológica \\ Federal do Paraná (UTFPR), Curitiba - PR
}

\section{RESUMO}

Apesar de ser uma ferramenta muito importante e que contribui significativamente para o sucesso de um projeto, a comunicação ainda é administrada de maneira ineficiente em diversas organizações, sobretudo nas do setor público; o qual possui características próprias que podem dificultar a execução dos processos de gerenciamento da comunicação de um projeto. Com base neste cenário, pode se levantar o seguinte problema: como os processos de gerenciamento das comunicações listados pelo PMBOK podem ser adaptados à realidade da gestão de projetos públicos? Por meio de pesquisa descritiva, interpretativa, qualitativa, bibliográfica e documental, o presente estudo procura responder a esta questão. Para isto foram relatadas as principais características do setor público, no que tange à gestão de projetos; expôs-se a importância das comunicações para os mesmos; foram listadas as práticas de gerenciamento de comunicação descritas no PMBOK; e relacionou-se estas práticas às peculiaridades encontradas nos projetos administrados por organizações públicas. O resultado final deste trabalho consiste na identificação das adaptações necessárias aos processos de gerenciamento das comunicações listados pelo PMBOK quando aplicados a projetos públicos.

Palavras-chave: Gerenciamento de projetos. Comunicação. Administração pública.

\section{Introdução}

Observa-se atualmente um ritmo crescente de mudanças e, em um ambiente tão competitivo, as organizações necessitam constantemente de projetos para criar ou realizar alguma inovação em seus processos, produtos, serviços ou até mesmo na sua estrutura interna (VERZUH, 2000). Se o projeto for gerenciado de maneira eficiente tornam-se maiores as chances de se alcançar os seus objetivos de forma satisfatória, pois esta prática permite calcular previamente diversos fatores, como custo, tempo e riscos, de modo a facilitar a tomada de decisões e de ações necessárias para contornar possíveis situações desfavoráveis (VARGAS, 2007).

Com o propósito de disseminar boas práticas de gerenciamento de projetos, o Project Management Institute (PMI) criou Um Guia do Conhecimento em Gerenciamento de Projetos (A Guide to the Project Management Body of Knowledge - PMBOK), o qual relaciona cinco 
grupos de processos de gerenciamento de projetos com nove áreas de conhecimento, resultando em 42 processos menores.

Uma das principais áreas de conhecimento, de acordo o PMI, a ser administrada pela equipe do projeto, é o gerenciamento das comunicações; um fator que é muito importante, pois a maior parte do tempo do gerente do projeto é despendida com a comunicação com os membros da equipe e com as demais partes interessadas. De modo que uma "comunicação eficaz cria uma ponte entre as diversas partes interessadas envolvidas no projeto" (PMI, 2008).

Infelizmente, segundo pesquisa realizada pelo PMI em 2011, os problemas de comunicação são relatados pelas organizações brasileiras como o problema mais frequente em projetos e também como a principal deficiência dos gerentes de projetos nas organizações.

Além disto, muitas instituições parecem ainda não adotar, de uma maneira geral, boas práticas de gerenciamento de projetos ao realizar alguma mudança ou inovação. Como é o caso dos órgãos públicos brasileiros, os quais, segundo a mesma pesquisa citada anteriormente, apresentam o dobro de alta resistência à gestão de projetos e concedem menos tempo e recursos adequados a um planejamento e controle efetivos, quando comparados ao resultado de todos os setores entrevistados. Esta pode ser uma das explicações do porquê, na administração pública, poucas vezes os projetos realizados alcançam metas de prazo, custo, qualidade e satisfação do cliente (PMI, 2011).

Considerando então a importância da comunicação no gerenciamento de projetos e as características intrínsecas da administração pública, como os processos de gerenciamento das comunicações listados pelo PMBOK podem ser adaptados à realidade da gestão de projetos públicos? Responder a este questionamento pode ajudar os gerentes e suas equipes a planejar e executar a comunicação de seus projetos de forma mais efetiva, fazendo com que os interesses e expectativas das partes interessadas sejam conhecidos e que as tarefas e papéis de cada membro da equipe sejam claros, evitando, assim, conflitos de informações, atrasos no projeto e entrega de resultados não condizentes com as expectativas do cliente.

Deste modo, o objetivo deste trabalho é identificar adaptações necessárias aos processos de gerenciamento das comunicações listados pelo PMBOK quando aplicados a projetos públicos. Para isto, pretende-se relatar as principais características do setor público, no que tange à gestão de projetos; expor a importância das comunicações para os mesmos; listar as práticas de gerenciamento de comunicação descritas no PMBOK; e relacionar estas práticas às peculiaridades encontradas nos projetos administrados por organizações públicas.

As duas primeiras seções deste artigo trazem um referencial bibliográfico sobre a gestão de projetos no setor público e sobre a comunicação dentro do gerenciamento de projetos, incluindo os processos presentes no PMBOK. Em seguida há a apresentação da metodologia utilizada e a discussão dos resultados. E por último são oferecidas as considerações finais do estudo. 


\section{0 gerenciamento de projetos na administração pública}

Os projetos de organizações públicas exigem alguns cuidados especiais por parte de seus gerentes, pois alguns diferenciais, como o cumprimento da legislação e a consideração por uma quantidade maior de partes interessadas - uma vez que um projeto público pode afetar uma comunidade inteira - devem ser observados (VERZUH, 2000). Além disto, alguns autores identificam barreiras no setor público como:

Falta de um foco claro no cliente; excesso de procedimentos; pessoas trabalhando individualmente ou em departamento isolados; excesso de alvos; falta de estratégia; crença geral em que os empregados trabalham demais e são mal remunerados; falta de entendimento dos efeitos de variação, fluxo do processo e visão sistêmica. (RADNOR; WALLEY, 2008 apud LIMA et al., 2010).

Vargas (2008) explica que entre as áreas pública e privada não há grande diferenciação entre o perfil e o tipo de trabalho desenvolvido na gestão de projetos. $\mathrm{O}$ que difere uma da outra é a estrutura que cada uma oferece. Sendo que, segundo o autor, a administração pública possui algumas limitações, como as restrições para a aquisição de bens e serviços, impostas pela legislação de licitações; as mudanças periódicas da alta cúpula da administração, que são acompanhadas, muitas vezes, da descontinuidade de projetos em andamento; e a visão comum de que os processos públicos são muitas vezes obscuros, o que facilitaria a dissimulação de erros intencionais cometidos pela equipe de projetos e a contratação de fornecedores desqualificados.

Já segundo o PMI (2006), os projetos públicos se diferenciam pelos seguintes aspectos: restrições legais, que impõe limites claros às ações dos órgãos públicos e de seus agentes, sendo que muitos atos necessitam de permissões legais; prestação de contas a um maior número de partes interessadas, que incluem - além das comuns a todos os projetos chefes do poder executivo, representantes de ministérios e de agências reguladoras, organizações com interesses especiais, imprensa e sociedade como um todo; e a utilização de recursos públicos, que são alocados conforme leis orçamentárias e políticas públicas e devem ser utilizados para melhorar os serviços públicos oferecidos à população, de modo que o sucesso de um projeto deste tipo é, na maioria das vezes, mensurado de acordo com os benefícios gerados à sociedade ao invés de ser medido pela renda ou economia geradas ao governo.

O quadro 1, apresentado a seguir, resume as principais distinções entre a gestão de projeto nos setores público e privado:

Quadro 1 - Principais diferenças entre as áreas pública e privada quanto ao gerenciamento de projetos

\begin{tabular}{|l|l|}
\hline \multicolumn{1}{|c|}{ ÁREA PRIVADA } & \multicolumn{1}{c|}{ ÁREA PÚBLICA } \\
\hline Tudo pode, exceto onde a lei proíbe & Tudo é proibido, exceto onde a lei permite \\
\hline Salários compatíveis ao mercado & Salários inadequados \\
\hline Maior disponibilidade de pessoal qualificado & Dificuldade de obtenção de pessoal qualificado \\
\hline Possível implantar política de incentivo & Difícil implantar política de incentivo \\
\hline $\begin{array}{l}\text { A estrutura do poder formal é próxima do } \\
\text { informal }\end{array}$ & $\begin{array}{l}\text { Maior distorção entre o poder formal e o } \\
\text { informal }\end{array}$ \\
\hline Baixa incidência de disfunção & Maior incidência de disfunção \\
\hline Organização voltada para objetivos & Evidência no desacordo com os objetivos \\
\hline
\end{tabular}




\begin{tabular}{|l|l|}
\hline \multicolumn{1}{|c|}{ ÁREA PRIVADA } & \multicolumn{1}{c|}{ ÁREA PÚBLICA } \\
\hline $\begin{array}{l}\text { Prioridade e objetivos, estabelecidos pela } \\
\text { diretoria }\end{array}$ & $\begin{array}{l}\text { Prioridades e objetivos negociados com a } \\
\text { sociedade }\end{array}$ \\
\hline Pouca burocracia & Presença marcante da burocracia \\
\hline $\begin{array}{l}\text { Alta administração sofre cobrança permanente } \\
\text { quanto aos objetivos e metas a serem atingidos }\end{array}$ & $\begin{array}{l}\text { A cobrança da sociedade é de caráter mais } \\
\text { subjetivo }\end{array}$ \\
\hline Continuidade administrativa mais permanente & $\begin{array}{l}\text { Risco quanto à quebra da continuidade } \\
\text { administrativa }\end{array}$ \\
\hline $\begin{array}{l}\text { Pouco frequente a paralisação de programas e } \\
\text { projetos por falta de recursos }\end{array}$ & $\begin{array}{l}\text { Frequentemente ocorre paralisação de } \\
\text { programas e projetos por falta de recursos }\end{array}$ \\
\hline $\begin{array}{l}\text { Decisão quanto aos objetivos centrados em } \\
\text { poucos órgãos }\end{array}$ & Maior dispersão quanto à tomada de decisão \\
\hline $\begin{array}{l}\text { Muito uso de ferramentas de planejamento e } \\
\text { controle }\end{array}$ & $\begin{array}{l}\text { Pouco uso das ferramentas de planejamento e } \\
\text { controle }\end{array}$ \\
\hline Voltada para a qualidade & Conceito de qualidade ainda incipiente \\
\hline Impulsionada pela competitividade & Baixa inserção na realidade da competição \\
\hline
\end{tabular}

Fonte: DINSMORE et al., 1998 (resumo adaptado) (apud KOLOTELO; CARVALHO, 2007).

\section{A comunicação no gerenciamento de projetos}

A comunicação é uma das principais áreas de conhecimento dentro do gerenciamento de um projeto e, para que alcance o seu propósito, deve ser administrada durante todas as suas fases: iniciação, planejamento, execução, monitoramento e controle, e encerramento. No entanto, muitas vezes, só há uma atenção com a comunicação durante o planejamento, havendo um descuido nas demais fases, de modo que ela passa a ser "reduzida ao mero fato de despachar: uma autorização escrita ou oral para começar o trabalho." (COSTA et al., 2007).

Esta constatação é corroborada pelo PMI (2008), que reforça a necessidade de revisão e aplicação contínua dos processos de comunicação. O Instituto explica que uma comunicação ineficaz e ineficiente pode causar problemas ao projeto, como: "atraso na entrega de mensagens, comunicação de informações confidenciais para o público incorreto ou falta de comunicação para algumas das partes interessadas necessárias." Do mesmo modo, Kolotelo e Carvalho (2007) defendem a importância da comunicação para a certificação de que o projeto está alinhado aos objetivos estratégicos da organização, e explicam que o sucesso do projeto depende muito da capacidade do gerente em se comunicar com clareza e precisão. Russo et al. (2005) acrescenta, ainda, que a comunicação envolve a "capacidade de escutar com abertura e enviar mensagens convincentes, partilhando informações e mantendo a receptividade tanto de boas quanto de más notícias."

Maximiano (2010) também acredita que a comunicação é fundamental para a organização e para as atividades de qualquer equipe de projetos, sendo que esta deve possuir as seguintes características: disposição para ouvir, sem a imposição de barreiras e com o comprometimento de receber informações de qualquer parte interessada; disposição para falar, superando o receio de se manifestar e evitando presumir que aquela informação não colaborará com o projeto; e organização pessoal para participar, com a imposição de normas de comunicação que facilitem a transmissão e a compreensão das informações, pois "uma equipe desorganizada comunica-se mal, e vice-versa." 
Levantamento realizado por Pimenta et al. (2005) demonstrou que a falta de informação pode desestabilizar um projeto, pois o desconhecimento dos fatos pode levar as partes interessadas a preencher as lacunas com suposições. Além disso, não basta que as informações sejam repassadas, elas precisam ser compreendidas por todos os envolvidos no projeto.

Alguns dos principais benefícios da comunicação dentro do gerenciamento de projetos, conforme resuma Vargas (2009), são: aumento do controle gerencial; agilidade das decisões; orientação da revisão da estrutura; melhora na capacidade de adaptação; possibilidade de desenvolver diferenciais competitivos e novas técnicas; e antecipação das situações desfavoráveis. Do mesmo modo, o autor cita as principais falhas desta área: "dados insuficientes ou não confiáveis; pouca sistematização; pouca importância dada à distribuição da informação; interesse voluntário em ocultar informações; e falta de um padrão de comunicação" (VARGAS, 2009).

Considerando a importância da gestão da comunicação para o projeto e com o objetivo de evitar os problemas citados anteriormente e tornar a comunicação mais eficaz e eficiente, o PMBOK (PMI, 2008) criou um capítulo exclusivo para os processos desta área de conhecimento. Neste capítulo são descritos os objetivos de cada processo; a principal fase do projeto em que cada um se enquadra; as informações e ações necessárias para se iniciar o processo (entradas), que, em alguns casos, se originam das saídas de outros processos desenvolvidos pelas demais áreas de conhecimento; as ferramentas e técnicas utilizadas para desenvolvê-lo; e os produtos ou documentos gerados ao fim de cada um (saídas). O quadro 2 traz um resumo interpretativo destas informações:

Quadro 2 - Resumo dos processos de gerenciamento das comunicações do projeto listados pelo PMBOK

\begin{tabular}{|c|c|c|c|c|c|}
\hline PROCESSO & OBJETIVOS & $\begin{array}{l}\text { FASE DO } \\
\text { PROJETO }\end{array}$ & ENTRADAS & $\begin{array}{c}\text { FERRAMENTAS } \\
\text { E TÉCNICAS }\end{array}$ & SAÍDAS \\
\hline $\begin{array}{l}\text { Identificar as } \\
\text { partes } \\
\text { interessadas }\end{array}$ & $\begin{array}{l}\text { - Identificar } \\
\text { todas as } \\
\text { pessoas ou } \\
\text { organizações } \\
\text { que possam } \\
\text { ser afetadas } \\
\text { pelo projeto; } \\
\text { - Documentar } \\
\text { as } \\
\text { informações } \\
\text { relevantes } \\
\text { relacionadas } \\
\text { aos seus } \\
\text { interesses, } \\
\text { envolvimen- } \\
\text { to e impacto } \\
\text { no sucesso } \\
\text { do projeto }\end{array}$ & Iniciação & $\begin{array}{l}\text { Relação das } \\
\text { partes } \\
\text { interessadas a } \\
\text { partir da análise } \\
\text { do termo de } \\
\text { abertura do } \\
\text { projeto, dos } \\
\text { contratos } \\
\text { firmados, da } \\
\text { cultura } \\
\text { organizacional } \\
\text { e do que foi } \\
\text { aprendido em } \\
\text { projetos } \\
\text { anteriores }\end{array}$ & $\begin{array}{l}\text { Análise e } \\
\text { avaliação do } \\
\text { impacto e } \\
\text { influência } \\
\text { gerados por cada } \\
\text { parte interessada, } \\
\text { com base em } \\
\text { coleta e análise } \\
\text { de dados e na } \\
\text { consulta de } \\
\text { grupos ou } \\
\text { pessoas } \\
\text { especializadas }\end{array}$ & $\begin{array}{l}\text { Registro das } \\
\text { partes } \\
\text { interessadas, } \\
\text { com as } \\
\text { informações } \\
\text { sobre sua } \\
\text { identificação, } \\
\text { avaliação, } \\
\text { interesses, } \\
\text { expectativas e } \\
\text { nível de } \\
\text { participação }\end{array}$ \\
\hline
\end{tabular}




\begin{tabular}{|c|c|c|c|c|c|}
\hline PROCESSO & OBJETIVOS & $\begin{array}{l}\text { FASE DO } \\
\text { PROJETO }\end{array}$ & ENTRADAS & $\begin{array}{l}\text { FERRAMENTAS } \\
\text { E TÉCNICAS }\end{array}$ & SAÍDAS \\
\hline $\begin{array}{l}\text { Planejar as } \\
\text { comunicações }\end{array}$ & $\begin{array}{l}\text { - Determinar } \\
\text { as } \\
\text { necessidades } \\
\text { de } \\
\text { informação } \\
\text { das partes } \\
\text { interessadas } \\
\text { no projeto; } \\
\text { - Definir uma } \\
\text { abordagem } \\
\text { de } \\
\text { comunicação }\end{array}$ & $\begin{array}{l}\text { Planeja- } \\
\text { mento }\end{array}$ & $\begin{array}{l}\text { Registro das } \\
\text { partes } \\
\text { interessadas e } \\
\text { conhecimento } \\
\text { acerca dos } \\
\text { fatores } \\
\text { ambientais da } \\
\text { empresa e do } \\
\text { que foi } \\
\text { aprendido em } \\
\text { projetos } \\
\text { anteriores }\end{array}$ & $\begin{array}{l}\text { Análise dos } \\
\text { tipos, formatos, } \\
\text { métodos e canais } \\
\text { de comunicação } \\
\text { possíveis e } \\
\text { necessários para } \\
\text { repassar as } \\
\text { informações }\end{array}$ & $\begin{array}{l}\text { Plano de } \\
\text { gerenciamento } \\
\text { das } \\
\text { comunicações, } \\
\text { com as } \\
\text { informações } \\
\text { sobre a } \\
\text { definição de } \\
\text { tipos, } \\
\text { formatos, } \\
\text { métodos e } \\
\text { canais de } \\
\text { comunicação } \\
\text { adotados }\end{array}$ \\
\hline $\begin{array}{l}\text { Distribuir } \\
\text { informações }\end{array}$ & $\begin{array}{l}\text { - Colocar as } \\
\text { informações } \\
\text { necessárias à } \\
\text { disposição } \\
\text { das partes } \\
\text { interessadas } \\
\text { no projeto, } \\
\text { conforme } \\
\text { planejado }\end{array}$ & Execução & $\begin{array}{l}\text { Plano de } \\
\text { gerenciamento } \\
\text { do projeto, } \\
\text { juntamente com } \\
\text { o plano das } \\
\text { comunicações, } \\
\text { relatórios de } \\
\text { desempenho do } \\
\text { andamento do } \\
\text { projeto, e } \\
\text { informações } \\
\text { institucionais } \\
\text { sobre projetos } \\
\text { anteriores }\end{array}$ & $\begin{array}{l}\text { Repasse das } \\
\text { informações a } \\
\text { partir de } \\
\text { diferentes meios, } \\
\text { métodos e } \\
\text { ferramentas }\end{array}$ & $\begin{array}{l}\text { Atualização } \\
\text { dos relatórios, } \\
\text { apresentações } \\
\text { e registros do } \\
\text { projeto. } \\
\text { Notificação e } \\
\text { feedback às } \\
\text { partes } \\
\text { interessadas. } \\
\text { Documentação } \\
\text { das lições } \\
\text { aprendidas }\end{array}$ \\
\hline $\begin{array}{l}\text { Gerenciar as } \\
\text { expectativas } \\
\text { das partes } \\
\text { interessadas }\end{array}$ & $\begin{array}{l}\text { - Comunicar- } \\
\text { se e interagir } \\
\text { com as partes } \\
\text { interessadas } \\
\text { para atender } \\
\text { às suas } \\
\text { necessidades } \\
\text { e solucionar } \\
\text { as questões à } \\
\text { medida que } \\
\text { ocorrerem }\end{array}$ & Execução & $\begin{array}{l}\text { Registro das } \\
\text { partes } \\
\text { interessadas. } \\
\text { Plano de } \\
\text { gerenciamento } \\
\text { do projeto, } \\
\text { juntamente com } \\
\text { o plano das } \\
\text { comunicações. } \\
\text { Conhecimentos } \\
\text { das questões } \\
\text { levantadas pelas } \\
\text { partes } \\
\text { interessadas, } \\
\text { das mudanças } \\
\text { ocorridas no } \\
\text { projeto e das } \\
\text { informações } \\
\text { históricas sobre } \\
\text { projetos } \\
\text { anteriores }\end{array}$ & $\begin{array}{l}\text { Gerenciamento } \\
\text { das expectativas } \\
\text { das partes } \\
\text { interessadas, } \\
\text { com o } \\
\text { esclarecimento e } \\
\text { solução das } \\
\text { questões } \\
\text { levantadas, } \\
\text { através de } \\
\text { habilidades } \\
\text { interpessoais e } \\
\text { de } \\
\text { gerenciamento, } \\
\text { por meio de } \\
\text { diferentes } \\
\text { métodos de } \\
\text { comunicação }\end{array}$ & $\begin{array}{l}\text { Solicitação de } \\
\text { mudanças e } \\
\text { atualização } \\
\text { nos } \\
\text { documentos } \\
\text { gerados } \\
\text { durante o } \\
\text { projeto, se } \\
\text { necessário }\end{array}$ \\
\hline
\end{tabular}




\begin{tabular}{|c|c|c|c|c|c|}
\hline PROCESSO & OBJETIVOS & $\begin{array}{c}\text { FASE DO } \\
\text { PROJETO }\end{array}$ & ENTRADAS & $\begin{array}{l}\text { FERRAMENTAS } \\
\text { E TÉCNICAS }\end{array}$ & SAÍDAS \\
\hline $\begin{array}{l}\text { Reportar o } \\
\text { desempenho }\end{array}$ & $\begin{array}{l}\text { - Coletar e } \\
\text { distribuir } \\
\text { informações } \\
\text { sobre o } \\
\text { desempenho, } \\
\text { incluindo } \\
\text { relatório de } \\
\text { andamento, } \\
\text { medições do } \\
\text { progresso e } \\
\text { previsões }\end{array}$ & $\begin{array}{l}\text { Monitora- } \\
\text { mento e } \\
\text { controle }\end{array}$ & $\begin{array}{l}\text { Plano de } \\
\text { gerenciamento } \\
\text { do projeto, } \\
\text { juntamente com } \\
\text { o plano das } \\
\text { comunicações. } \\
\text { Levantamento } \\
\text { de informações } \\
\text { sobre o } \\
\text { desempenho do } \\
\text { trabalho } \\
\text { desenvolvido. } \\
\text { Conhecimento } \\
\text { sobre o } \\
\text { cronograma e } \\
\text { orçamento do } \\
\text { projeto }\end{array}$ & $\begin{array}{l}\text { Análise do } \\
\text { desempenho, } \\
\text { qualidade, } \\
\text { variação e } \\
\text { impacto do } \\
\text { trabalho } \\
\text { desenvolvido. } \\
\text { Previsão do } \\
\text { desempenho } \\
\text { futuro, com base } \\
\text { no que foi } \\
\text { desenvolvido até } \\
\text { então }\end{array}$ & $\begin{array}{l}\text { Relatórios de } \\
\text { desempenho, } \\
\text { incluindo } \\
\text { dados de } \\
\text { tempo e custo. } \\
\text { Solicitação de } \\
\text { mudanças e } \\
\text { atualização } \\
\text { nos } \\
\text { documentos } \\
\text { gerados } \\
\text { durante o } \\
\text { projeto, se } \\
\text { necessário }\end{array}$ \\
\hline
\end{tabular}

Fonte: Autoria própria, baseado no Guia PMBOK (PMI, 2008).

\section{Metodologia}

Para alcançar o objetivo principal de identificar adaptações necessárias aos processos de gerenciamento das comunicações listados pelo PMBOK quando aplicados a projetos públicos, foi realizada uma pesquisa descritiva e interpretativa e de abordagem qualitativa. Sendo que os dados foram coletados por meio de pesquisa bibliográfica e documental.

\section{Resultados}

A partir das informações apreendidas sobre a gestão de projetos no setor público e acerca do gerenciamento das comunicações do projeto, foi possível reconhecer as principais particularidades deste setor que obstaculizam a gestão de uma comunicação eficaz e eficiente de um projeto e que, portanto, demandam adaptações dos processos de comunicação.

Deste modo esta pesquisa permitiu relacionar estas características aos processos de comunicação listados pelo PMBOK, o que levou à identificação de possíveis adaptações necessárias a estes processos, conforme segue:

- Identificar as partes interessadas. Considerando que um projeto desenvolvido por uma instituição pública possui um maior número de partes interessadas, entre elas a sociedade como um todo, é essencial que a equipe esteja aberta à contribuição de qualquer pessoa ou organização. Isto pode ser feito através da disponibilização de um canal oficial para dúvidas e sugestões e também por meio de consultas em assembléias ou reuniões com determinados públicos. Pois, sem possuir, no início do projeto, uma visão clara e objetiva das expectativas das comunidades que serão atingidas pelo projeto, direta ou indiretamente, corre-se o risco de entregar, no final, um resultado inadequado ou insuficiente. Além disso, igualmente deve-se considerar as possíveis ideias da imprensa acerca do projeto, visto que ela possui grande influência sobre a opinião da população e tem o papel de fiscalizar as ações públicas.

- Planejar as comunicações. Para se determinar as informações que serão repassadas e os meios utilizados, é imprescindível uma análise profunda da legislação acerca daquele 
projeto, pois pode haver casos em que a publicidade ou a confidencialidade sejam obrigatórias e que os meios de comunicação já sejam determinados, como, por exemplo, publicações em diários oficiais. Este processo também deve incluir a previsão de uso de canais de comunicação amplos e acessíveis, pois a administração pública deve sempre prestar contas a toda a sociedade.

- Distribuir informações. Com o objetivo de derrubar a visão de obscuridade dos procedimentos públicos, as informações devem ser repassadas da maneira mais clara e objetiva possível. Ademais é importante se certificar de que os membros da equipe compreendem as informações repassadas e as suas funções dentro do projeto, uma vez que há a existência de um foco no trabalho individual e uma maior dispersão quanto à tomada de decisões. Do mesmo modo, a linguagem utilizada para informar a população deve ser simples, pois é preciso se certificar de que todo cidadão compreenderá a mensagem transmitida, independente da sua posição social.

- Gerenciar as expectativas das partes interessadas. Neste processo também é importante se considerar o maior número de partes interessadas, mas igualmente há a necessidade de se observar as seguintes características encontradas no setor público: ocorrência frequente de paralisação de programas e projetos por falta de recursos, presença marcante da burocracia, restrições legais e risco quanto à quebra da continuidade administrativa. Afinal estas particularidades podem gerar atrasos e mudanças em diversos outros processos das demais áreas de conhecimento que devem ser administradas durante um projeto, o que pode frustrar as expectativas das partes interessadas. Por isto a equipe deve possuir conhecimento sobre estas questões políticas e legais, de modo a poder esclarecer as dúvidas levantadas de forma adequada.

- Reportar o desempenho. Considerando as imposições legais e a burocracia existentes no setor público, além da demonstração periódica do desempenho alcançado e esperado, pode haver a necessidade de se produzir uma prestação de contas, ao fim do projeto, mais profunda e complexa. Há, inclusive, diversas normas que regulamentam este procedimento.

\section{Considerações finais}

$\mathrm{O}$ gerenciamento de projetos parece ser uma ferramenta ainda incipiente nas organizações públicas. E muitos autores, corroborados por pesquisas, como a realizada pelo PMI em 2011 e citada anteriormente, apontam a administração da comunicação como uma das principais áreas problemáticas dos projetos públicos, senão a mais, conforme defende Clemente e Wekerlin (2002): "Comunicar os objetivos, métodos e técnicas dos projetos de forma a efetivamente obter as ações necessárias é, sem dúvida, o maior desafio no setor público".

É fato que as organizações públicas, como já foi demonstrado, possuem características próprias que requerem um gerenciamento de projetos diferenciado do executado por empresas privadas. No entanto, nem todas estas particularidades devem ser vistas como barreiras intransponíveis, pois a necessidade de se gerenciar um projeto de modo eficaz e eficiente exige a busca de adaptações dos processos de gerenciamento a esta realidade.

No caso das comunicações não é diferente. Este estudo demonstrou como é importante e possível realizar um gerenciamento adequado, superando os obstáculos existentes no setor público através da adaptação dos processos sugeridos pelo PMBOK. 
Espera-se que este trabalho contribua para o estudo do gerenciamento de projetos dentro da administração pública e que sirva de inspiração e embasamento para futuras pesquisas nesta área tão recente, mas tão desafiadora.

\section{Referências}

CLEMENTE, Ademir; WEKERLIN, Jorge Eduardo. O lado humano dos projetos. In: CLEMENTE, Ademir (Org.). Projetos empresariais e públicos. São Paulo: Atlas, 2002.

COSTA, Adolfo C. F.; JUNGLES, Antônio E., OLIVEIRA, Ricardo R. de. Diretrizes para o desenvolvimento da comunicação no gerenciamento de projetos: uma abordagem da teoria da ação como perspectiva da linguagem. In: ENCONTRO DE TECNOLOGIA DE INFORMAÇÃO E COMUNICAÇÃO NA CONSTRUÇÃO CIVIL, 3, 2007, Porto Alegre. Anais eletrônicos... Disponível em: <http://www6.ufrgs.br/norie/tic2007/artigos/ A1087.pdf>. Acesso em: 18 fev. 2012.

KOLOTELO, Jorge Luciano Gil; CARVALHO, Hélio Gomes. O papel da comunicação na gestão por projetos: um estudo de caso em empresa paraestatal. Revista Gestão Industrial, Ponta Grossa, v. 3, n. 2, 2007. Disponível em: <http://www.pg.utfpr.edu.br/depog/periodicos/index.php/revistagi/article/view/71/68>. Acesso em: 16 fev. 2012.

LIMA, Mariana M. X. de; BISIO, Larissa R. de A.; ALVES, Thaís. da C. L. Mapeamento do fluxo de valor do projeto executivo de arquitetura em um órgão público. Gestão \& Tecnologia de Projetos, São Paulo, v. 5, n. 1, jul. 2010. Disponível em: <http://www.arquitetura.eesc.usp.br/posgrad/gestaodeprojetos/jornal2/index.php/ gestaodeprojetos/article/view/113/156>. Acesso em: 15 fev. 2012.

MAXIMIANO, Antonio Cesar Amaru. Administração de projetos: como transformar ideias em resultados. 4 ed. São Paulo: Atlas, 2010.

PIMENTA, Rosângela B; LIMA, Isaura A. de; DERGINT, Dario E. A. Comunicação eficaz: competência gerencial estratégica na condução de equipes de projetos. Revista Gestão Industrial, Ponta Grossa, v. 1, n. 3, 2005. Disponível em: <http://revistas.utfpr.edu.br/pg/index.php/revistagi/article/view/153>. Acesso em: 16 fev. 2012.

PROJECT MANAGEMENT INSTITUTE (PMI). Government extension to the PMBOK ${ }^{\circledR}$ guide third edition. Newtown Square, PA: PMI, 2006.

PMSURVEY.ORG 2011 Edition: Project Management Institute Chapters. [S.1.]: PMI, 2011. Disponível em: <www.pmsurvey.org>. Acesso em: 13 fev. 2012.

Um guia do conhecimento em gerenciamento de projetos (guia $\mathrm{PMBOK}^{\circledR}$ ). 4. ed. Newtown Square, PA: PMI, 2008.

RUSSO, Rosária de F. S. M.; RUIZ, Jose M.; CUNHA, Rosana P. da. Liderança e influência nas fases da gestão de projetos. Revista Produção, São Paulo, v. 15, n. 3, set./dez. 2005. Disponível em: <http://www.scielo.br/ scielo.php?script=sci_abstract\&pid=S0103-65132005000300007\&lng=pt\&nrm=iso\&tlng= pt $>$. Acesso em: 18 fev. 2012.

VARGAS, Ricardo Viana. Gerenciamento de projetos no setor público. [S.1.: s.n], 2008. Podcast (5 min). Disponível em: <http://www.ricardo-vargas.com/pt/podcasts/publicsector/>. Acesso em: 15 fev. 2012.

2007.

Manual prático do plano de projeto: utilizando o PMBOK Guide. 3. ed. Rio de Janeiro: Brasport,

Por que gerenciar as comunicações? [S.1.: s.n], 2009. 13 slides: color. Slides gerados a partir do software PowerPoint. Disponível em: <http://www.ricardo-vargas.com/pt/downloads/>. Acesso em: 15 fev. 2012. VERZUH, Eric. MBA compacto, gestão de projetos. Rio de Janeiro: Elsevier, 2000. 